\title{
Aspectos envolvidos na biodegradação da atrazina sob diferentes condições de
}

\section{oxirredução}

\author{
Overview of atrazine biodegradation under different oxidation-reduction conditions \\ Aspectos implicados en la biodegradación de la atrazina en diferentes condiciones de oxidación- \\ reducción
}

Recebido: 29/06/2021 | Revisado: 06/07/2021 | Aceito: 08/07/2021 | Publicado: 18/07/2021

Tális Pereira Matias

ORCID: https://orcid.org/0000-0002-3565-0295

Universidade Federal de Alfenas, Brasil

E-mail: talismatias12@gmail.com

Juliana Kawanishi Braga

ORCID: https://orcid.org/0000-0002-5500-9008

Universidade Federal de Alfenas, Brasil

E-mail: jukawanishi@gmail.com

Leonardo Henrique Soares Damasceno

ORCID: https://orcid.org/0000-0003-4614-0570

Universidade Federal de Alfenas, Brasil

E-mail: leonardo@damasceno.eng.br

Gunther Brucha

ORCID: https://orcid.org/0000-0002-0768-5773

Universidade Federal de Alfenas, Brasil

E-mail: gunther.brucha@unifal-mg.edu.br

\begin{abstract}
Resumo
O uso indiscriminado do herbicida atrazina no Brasil e no mundo apresenta diversos efeitos adversos a saúde humana e aos ecossistemas, podendo ser encontrado no solo, nas águas subterrâneas, no ar e também nos seres vivos, o que justifica pesquisas voltadas à biodegradação, impactos e características deste composto. O presente trabalho, por meio de uma revisão da literatura, mostra que a biodegradação da atrazina pode ocorrer através de diferentes condições de oxirredução, com a participação de consórcios microbianos aeróbios e anaeróbios, gerando diferentes intermediários metabólitos, como a hidroxiatrazina, $\mathrm{N}$-isopropylammilide, ácido cianúrico, biureto, alofanato e uréia. Além disso, esta revisão mostra microrganismos que já foram detectados com o potencial de degradação deste composto utilizando a atrazina como fonte de carbono e/ou nitrogênio, e os seus intermediários metabólicos formados durante os processos aeróbios e anaeróbios de degradação, assim como os principais genes responsáveis pela síntese das enzimas envolvidas na degradação deste composto.
\end{abstract}

Palavras-chave: Herbicidas; Microbiologia; Agricultura; Solo; Águas subterrâneas.

\begin{abstract}
The indiscriminate use of the herbicide atrazine in Brazil and in the world has several adverse effects on human health and ecosystems, which can be found in soil, groundwater, in the air and also in living beings, which justifies research focused on biodegradation, impacts and characteristics of this compound. Our work, through a literature review, shows that atrazine's biodegradation can occur through different oxidation reduction conditions, with the participation of aerobic and anaerobic microbial consortia, generating different degradation metabolite intermediates, such as hydroxyatrazine, $\mathrm{N}$-isopropylammilide, cyanuric acid, biuret, allophanate and urea. In addition, we show microorganisms that have already been detected with the potential for degradation of this compound using atrazine as a source of carbon and / or nitrogen, and its metabolic intermediates formed during aerobic and anaerobic degradation processes, as well as the main genes responsible for synthesis of enzymes involved in the degradation of this compound.
\end{abstract}

Keywords: Herbicides; Microbiology; Agriculture; Soil; Groundwater.

\section{Resumen}

El uso indiscriminado del herbicida atrazina en Brasil y en todo el mundo tiene varios efectos adversos sobre la salud humana y los ecosistemas, pudiendo encontrarse en el suelo, las aguas subterráneas, el aire y también en los seres vivos, lo que justifica la investigación dirigida a la biodegradación, impactos y características de esta. compuesto. El presente trabajo, a través de una revisión de la literatura, muestra que la biodegradación de la atrazina puede ocurrir a través de diferentes condiciones de oxidación-reducción, con la participación de consorcios microbianos aeróbicos y 
anaeróbicos, generando diferentes metabolitos intermedios, tales como hidroxiatrazina, $\mathrm{N}$-isopropilammilida, ácido cianúrico, biuret, alofanato y urea. Además, esta revisión muestra microorganismos que ya han sido detectados con potencial de degradación de este compuesto utilizando atrazina como fuente de carbono y / o nitrógeno, y sus intermediarios metabólicos formados durante los procesos de degradación aeróbica y anaeróbica, así como los genes principales. responsable de la síntesis de enzimas implicadas en la degradación de este compuesto.

Palabras clave: Herbicidas; Microbiología; Agricultura; Suelo; Agua subterránea.

\section{Introdução}

Os agrotóxicos, amplamente utilizados na lavoura, apresentam riscos à saúde e ao meio ambiente o que justifica a importância de estudos, pesquisas, monitoramento e controle destes produtos no meio ambiente (Amaro et al., 2021; Matias et al., 2019). O uso de agrotóxicos no Brasil se justifica na melhoria agrícola, sendo a atrazina utilizada em diversos países pelo mundo. Nos últimos 50 anos de uso desse defensivo agrícola, ela se destacou por seus resultados eficazes no controle de ervas daninhas na lavoura. (Campanari, 2017). Entretanto, esses produtos podem apresentar características danosas aos seres humanos e ao meio ambiente, como é o caso da atrazina, um herbicida amplamente utilizado no Brasil desde meados de 1958, que apresenta toxicidade e outros efeitos adversos à saúde humana e aos ecossistemas (Ma et al., 2017; Vail et al., 2014).

Segundo o Boletim Nacional de Comercialização de Agrotóxicos feito pelo Ibama, de 2014 a 2016 o consumo de atrazina no Brasil dobrou, passando de 13.911,37 toneladas (ton) de ingrediente ativo (i.a.) para 28.615,70 ton de i.a.. De 2018 para 2019 houve uma redução de 28.799,34 ton de i.a. para 23.429,38 ton de i.a., 5369,96 ton a menos do que o ano anterior (2018). Entretanto, os números ainda são altos, e mantém a atrazina como um dos agrotóxicos mais vendidos entre 2009 e 2019, ocupando, em média destes 10 anos, o $3^{\circ}$ lugar entre os i.a. mais vendidos no país. Antes mesmo deste aumento no consumo, a atrazina já foi detectada em áreas degradadas correspondentes a locais de intensa atividade agrícola, nas regiões centrais e sul do estado de Goiás, Mato Grosso e no Rio Paraíba do Sul (RJ) próximo a áreas de lavoura de cana (Dellamatrice \& Monteiro, 2014).

Na Bacia Hidrográfica do Paraná 3, a presença de atrazina é alvo de preocupação e os impactos deste herbicida na saúde humana, por meio da ingestão de águas contaminadas, foi discutido no Plano da Bacia Hidrográfica do Paraná 3 feito em 2014, em que um total de 250 óbitos infantis associados a má formação fetal foram levantados na região. Embora não haja comprovação de ligação direta entre os casos de óbito e a contaminação de água local com atrazina, a presença deste composto em corpos d'água acessíveis a população deve ser tratada com atenção.

A presença deste produto em lençóis freáticos e em outros corpos d'água se justifica pela sua aplicação em altas concentrações, ao regime intenso de chuvas, aos tipos de solos, topografia, declividade do terreno, e suas propriedades orgânicas. Desta forma, informações sobre a degradação do herbicida atrazina são importantes para lidar com a problemática que envolve este composto (Dellamatrice \& Monteiro, 2014).

A degradação microbiana da atrazina é bem conhecida em condições aeróbias cuja degradação ocorre sobre a presença de oxigênio molecular como receptor de elétrons utilizando a atrazina como doador de elétrons em processos sequenciais de reações bioquímicas (Kabra et al., 2014; Kolekar; Phugare; Jadhav., 2014). Todavia conforme as características ambientais da região em que este poluente está presente, este composto pode ser lixiviado atingindo zonas mais profundas do solo e águas subterrâneas, onde o potencial de oxirredução é característico de condições anaeróbias (Tomassoni et al., 2014).

Os poucos trabalhos que relatam a degradação anaeróbia destes herbicidas (Douglass, Radosevich \& Tuovinen 2014; Tuovinen et al. 2015; Cecilia \& Maggi 2016; Matias et al., 2019) destacam a dificuldade de microrganismos anaeróbios em degradar este composto, e por serem poucos os trabalhos que dissertam sobre o tema, permanece uma lacuna no conhecimento necessário para o avanço no tratamento de ambientes anaeróbios impactados com este herbicida.

Portanto, devido aos riscos de impactos ambientais e aos danos potenciais à saúde humana, medidas que visem a eliminação, mineralização ou degradação da atrazina em subprodutos que representem impactos insignificantes são de extrema 
importância nos ambientes contaminados com este herbicida (Tomassoni et al., 2014).

Considerando uso da atrazina na agricultura e o seu potencial de contaminar solos profundos e águas subterrâneas, o presente trabalho tem como objetivo realizar um levantamento bibliográfico sobre as principais características da atrazina, trazendo informações sobre a sua biodegradação em diferentes condições de oxirredução (aeróbio, desnitrificação, sulfetogênese e metanogênese), os intermediários metabólicos produzidos durante a biodegradação e os genes que expressam enzimas específicas envolvidas no processo de degradação deste herbicida, fornecendo assim, uma visão importante dos processos de biodegradação da atrazina à pesquisadores e gestores ambientais que atuem na área de biorremediação, agricultura, manejo do solo, de poluentes emergentes e afins.

\section{Metodologia}

A abordagem metodológica utilizada neste trabalho consiste em uma revisão bibliográfica (Pereira et al., 2018) visando contemplar o estado da arte sobre a atrazina e os principais aspectos que sobre a biodegradação deste composto. As primeiras partes do texto contêm informações fundamentais para a compreensão e justificativa do aprofundamento de pesquisas sobre a biodegradação da atrazina, contemplando as características gerais deste agrotóxico, principais impactos e interações com variáveis ambientais, visando enfatizar a importância da implementação de medidas de controle e monitoramento ambiental de áreas expostas a atrazina em função das suas propriedades químicas e efeitos danosos a saúde e ao meio ambiente. Em seguida, realiza-se um aprofundamento sobre os processos de biodegradação e os principais aspectos envolvidos neste processo, mostrando as variações de biodegradação em diferentes condições de oxirredução, com a finalidade de fortalecer as bases teóricas de pesquisadores e profissionais da área.

\section{Resultados e Discussão}

\subsection{Características da atrazina}

Atrazina (2-cloro-4-2-isopropilamino-6-etilamino-striazina) é um herbicida amplamente comercializado no Brasil, especialmente em culturas de milho, soja, cana-de-açúcar e também de gramíneas e outros cultivos, tanto em pré quanto em pós emergência, atuando no controle de ervas daninhas. A fórmula estrutural da atrazina é apresentada na Figura 1, e a Tabela 1 caracteriza a atrazina (Cecilia \& Maggi, 2016; Ma et al., 2017; Tuovinen et al., 2015).

Figura 1. Fórmula estrutural da atrazina.

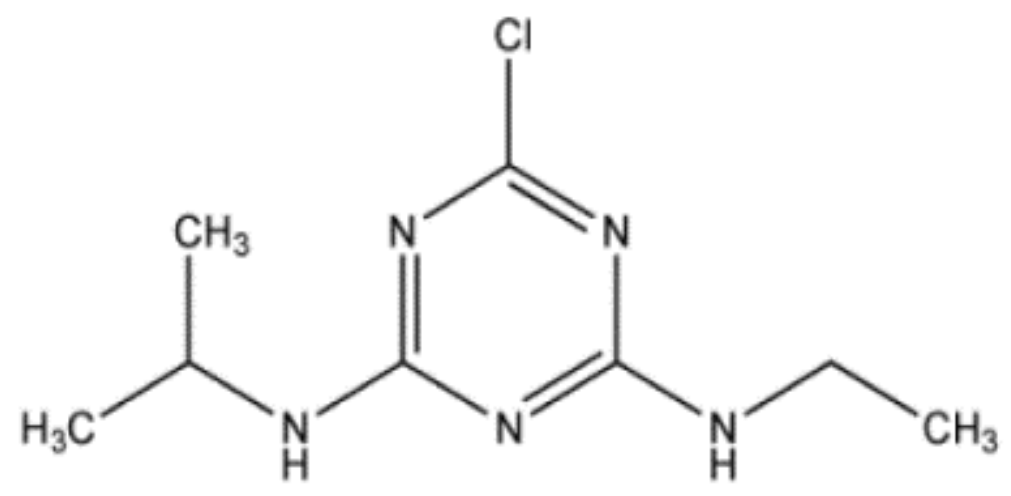

Fonte: USEPA (2007). 
Tabela 1. Características gerais e propriedades físico-químicas da atrazina.

\begin{tabular}{|c|c|}
\hline \multicolumn{2}{|l|}{ Características Gerais da Atrazina } \\
\hline Ingrediente ativo ou nome comum & Atrazina \\
\hline Nome químico & $\begin{array}{l}\text { 6-chloro- } \mathrm{N}^{2} \text {-ethyl- } \mathrm{N}^{4} \text {-isopropyl-1,3,5-triazine-2,4- } \\
\text { diamineisopropyl-1,3,5-triazine-2,4-diamine }\end{array}$ \\
\hline Fórmula bruta & C8H14ClN5 \\
\hline Grupo químico & Triazina \\
\hline Classe & Herbicida \\
\hline Classificação toxicológica & Classe III \\
\hline Modo de ação & $\begin{array}{l}\text { Ação seletiva, sistêmica, com atividade residual e foliar. } \\
\text { Inibe a fotossíntese (fotossistema II). }\end{array}$ \\
\hline Massa molecular & $215.68 \mathrm{~g} / \mathrm{mol}$ \\
\hline Detalhes de formulação e aplicação & $\begin{array}{l}\text { Disponível em uma variedade de formulações, incluindo } \\
\text { fluidos secos fluidos, líquidos fluidos, líquidos, dispersíveis } \\
\text { em água. }\end{array}$ \\
\hline Solubilidade & 35 mg/L em água $\left(20^{\circ} \mathrm{C}\right)$ \\
\hline \multirow{4}{*}{ Solubilidade em solventes orgânicos } & $24000 \mathrm{mg} / \mathrm{L}\left(20^{\circ} \mathrm{C}\right)$ Acetato de Etilo \\
\hline & $28000 \mathrm{mg} / \mathrm{L}\left(20^{\circ} \mathrm{C}\right)$ Diclorometano \\
\hline & $400 \mathrm{mg} / \mathrm{L}\left(20^{\circ} \mathrm{C}\right)$ Tolueno \\
\hline & $110 \mathrm{mg} / \mathrm{L}\left(20^{\circ} \mathrm{c}\right)$ Hexano \\
\hline Ponto de ebulição & Decompõe-se antes de ferver $\left(100^{\circ} \mathrm{C}\right)$ \\
\hline Ponto de Fulgor & Não é altamente inflamável \\
\hline \multirow{2}{*}{$\begin{array}{l}\text { Coeficiente de partição octanol-água a } \mathrm{pH} \\
7,20^{\circ} \mathrm{C}\end{array}$} & P $5.01 \times 10^{-2}$ \\
\hline & Log P 2,7 (moderado) \\
\hline Densidade aparente & $1,23 \mathrm{~g} / \mathrm{mL}$ \\
\hline Constante de dissociação $\mathrm{pKa}\left(25^{\circ} \mathrm{C}\right)$ & 1,7 \\
\hline Pressão de vapor $\mathrm{mPa}\left(20^{\circ} \mathrm{C}\right)$ & 0,039 (Baixa volatilidade) \\
\hline Índice potencial de lixiviação & 3,20 (Alta lixiviabilidade) \\
\hline
\end{tabular}

Fonte: Adaptado de: ANVISA (2016); IUPAC (2018).

A família S-triazinas, a qual a atrazina se enquadra, pode ser classificada em três grupos distintos, clorotriazinas, metoxitriazinas e metiltiotriazinas, e estes herbicidas normalmente são sólidos brancos cristalinos, fracamente básicos, com baixa solubilidade em água e alta solubilidade em solventes orgânicos. Normalmente são estáveis na fase sólida e em solução apresentam baixa pressão de vapor em condições mesotérmicas (Bonfleur, 2010).

A atrazina é um composto polar, fracamente básico, estável, em função de seu anel heterocíclico, a sua solubilidade em água praticamente independe do pH, embora em soluções cujo o pH é 2,0 a solubilidade aumente (Javaroni et al., 2016). Este composto é considerado persistente devido a sua solubilidade moderada e ao seu coeficiente de participação de sorção do solo ser baixo $(\mathrm{Kd}=3,7 \mathrm{~L} / \mathrm{kg})$, o que significa que este composto não é facilmente adsorvido pelo solo, sendo considerado móvel (Sene et al., 2010). Portanto essas características definem seu alto potencial de escoamento, hidrólise lenta e adsorção moderada pela matéria orgânica e argila (Neiverth, 2015; Silva, 2014).

Desta forma, considerando as características gerais da atrazina, seu uso e comercialização no Brasil, destaca-se a importância do conhecimento destes dados para que medidas de manejo e monitoramento ambiental sejam direcionadas para evitar ou minimizar os danos reais e potenciais deste composto. 


\subsection{Impactos da atrazina na saúde humana}

A União Internacional de Química Pura e Aplicada, no dia 23 de maio de 2018, atualizou a base de dados sobre agroquímicos, e destaca como principais efeitos da atrazina à saúde humana o seu potencial carcinogênico, indução ao coma, colapso circulatório, sangramento gástrico, insuficiência renal, perturbação no metabolismo da testosterona e problemas endócrinos: inibição androgênica e efeito estrogênico fraco.

Já foram detectados efeitos danosos deste herbicida ao ser humano, principalmente nos sistemas endócrino, nervoso central, imunológico e reprodutivo para concentrações entre 5 e $10 \mu \mathrm{g} / \mathrm{L}$ no ambiente (Douglass et al., 2014). Atrazina foi detectada em 4 de 5 pontos de coleta nas águas do Rio Pardo (variando de: 0,16-0,32 $\mu \mathrm{g} / \mathrm{L}$ ) abaixo dos limites estabelecidos pela legislação brasileira $(2,0 \mu \mathrm{g} / \mathrm{L})$, mas acima dos níveis permitidos pela União Europeia $(0,1 \mu \mathrm{g} / \mathrm{L})$. Para o valor encontrado, riscos de saúde associados ao contato primário foram excluídos, embora os autores enfatizem que podem haver riscos no caso de ingestão de águas contaminadas (Machado et al., 2018). Por meio destas pesquisas ficam claros os riscos atrelados ao uso indiscriminado da atrazina para a saúde, o que fortalece a necessidade da revisão de medidas regulamentadoras para o uso e comercialização deste produto químico.

\subsection{Impactos ambientais da atrazina}

A atrazina apresenta diversas propriedades prejudiciais aos ecossistemas e aos seres vivos, pois apresenta toxicidade moderada, efeitos carcinogênicos, mutagênico, teratogênico, podendo causar alterações no desenvolvimento do feto, problemas reprodutivos, e alteração nos nichos ecológicos em consequência desses efeitos adversos. É um poluente orgânico ubíquo, que pode ser encontrado no ar, no solo, e também em águas superficiais e subterrâneas (Kolekar et al., 2014; Zhang et al., 2015).

Este herbicida também pode ser incorporado e propagado em cadeias tróficas, podendo alterar uma ampla gama de espécies vegetais e animais, levando o ecossistema ao desequilíbrio, além da geração de uma pluma de contaminação, derivada da mobilidade deste composto no solo e em corpos d' água (Kanissery \& Sims, 2011; Kumar \& Philip, 2004). A toxicidade da $\begin{array}{llllllllll}\text { atrazina para ratos é Via Oral (DL } 50): & 1.750 \quad \mathrm{mg} / \mathrm{kg} ; & 3.080 & \mathrm{mg} / \mathrm{kg}\end{array}$ Via Cutânea (DL 50): LDLo: $550 \mathrm{mg} / \mathrm{kg}$, para coelhos Via Oral (DL 50): $750 \mathrm{mg} / \mathrm{kg}$; Via Cutânea (DL 50): $7.500 \mathrm{mg} / \mathrm{kg}$ e para organismos aquáticos Microcystis aeruginosa: início de inibição da multiplicação celular a 0,003 mg/L (CETESB, 2018).

Essas informações corroboram para a implementação de medidas de gestão que preconizem o princípio da prevenção e precaução, uma vez que os riscos da ocorrência e agravação de impactos ambientais derivados da atrazina são grandes, podendo causar desestabilização nos ecossistemas.

\subsection{Comportamento ambiental da atrazina}

As características do solo podem afetar a biodegradação deste pesticida, tal como a sua persistência no ambiente, uma vez que variáveis como $\mathrm{pH}$, e umidade interferem nas ligações químicas do solo com o pesticida, tal como a sua adsorção físico-química. Se a atrazina encontra-se adsorvida na fase sólida do solo, ela não está realmente disponível para os microrganismos, que são capazes de metabolizar substâncias apenas na solução do solo, o que aumenta a persistência do poluente no meio, ficando sujeito a processos de lixiviação para as camadas mais profundas do solo sem sofrer os processos de degradação biológica (Douglass et al., 2014; Cecilia \& Maggi, 2016; Tuovinen et al., 2015).

As condições do solo também interferem na movimentação deste micropoluente, a presença de colóides orgânicos no solo contribui para a retenção da atrazina, assim como solos ricos em motmorilomita, mineral 2:1 com maior capacidade de troca de cátions (CTC). Desta forma, solos pobres em matéria orgânica e com baixa CTC apresentam maior suscetibilidade a lixiviação deste herbicida solúvel (Almeida \& Guimarães, 2017; Souza et al., 2018).

A atrazina pode persistir nos solos e em águas subterrâneas por décadas, e o seu comportamento no ambiente pode 
variar conforme o tipo de solo em que ela se encontra, tal como as condições ambientais, como eventos de precipitação, que podem lixiviar este poluente para as águas subterrâneas e superficiais, temperatura e entre outros parâmetros ambientais capazes de influenciar o seu processo de biodegradação (Furlan et al., 2016; Cecilia \& Maggi, 2016; Swissa et al., 2015).

Em ambientes naturais a meia-vida da atrazina é reportada entre 4 e 385 dias em solos, ou mais em aquíferos de solos profundos, podendo variar também entre 10 e 105 dias em águas superficiais, apresentando, em média, uma meia-vida de 4 dias em condições aeróbias (Cecilia \& Maggi, 2016). Outros autores afirmam que a variação da meia-vida da atrazina pode ficar entre dois meses até seis anos, com possíveis variações conforme as condições ambientais e tipo de solo (Furlan et al., 2016).

Quanto mais profunda a camada de solo em que este herbicida se encontra, mais complexo é o seu processo de biodegradação. Todavia, acredita-se que na maioria dos solos a biodegradação seja o principal método de decomposição da atrazina, pois pode ocorrer de forma natural (Freeman \& Thanki, 2017). Outros processos como a desalogenação química abiótica em solos com pH baixo também pode ocorrer, além de adsorção por compostos de afinidade química no solo com a atrazina (Hunter \& Shaner, 2009).

Devido aos diversos efeitos adversos à saúde e à manutenção dos ecossistemas, a União Europeia como medida de cautela, proibiu o uso deste pesticida em 2004. Entretanto em países como China, Austrália e Brasil, este herbicida ainda é amplamente comercializado (Cecilia \& Maggi, 2016). Como no Brasil, os órgãos regulamentadores estabelecem que os níveis de atrazina em água doce não devem ser superiores a 2,0 $\mu \mathrm{g} / \mathrm{L}$ (CONAMA 357, 2005), isso justifica a importância do controle quantitativo deste micropoluente e da sua degradação em compostos inofensivos à saúde e ao meio ambiente (Neiverth, 2015). Desta forma, o entendimento da dinâmica ambiental da atrazina pode ser útil para a tomada de decisão sobre o uso, limites ambientais aceitos e direcionamentos sobre protocolos e manejos da atrazina, considerando a diversidade das variáveis ambientais que interagem com ela.

\subsection{Biodegradação da atrazina}

Em uma determinada área contaminada, os microrganismos nativos podem desenvolver a capacidade de degradar contaminantes, entretanto é possível que haja a necessidade de projetos específicos de engenharia para promover condições favoráveis aos processos biológicos e obter melhores resultados em um intervalo de tempo menor, uma vez que a biodegradação pode ser afetada por processos intrínsecos e extrínsecos de cada microrganismo de metabolizar substâncias (Berticelli et al., 2016; Gargouri et al., 2015; Rodr, 2015).

A atrazina pode ser utilizada como fonte de carbono e/ou nitrogênio pelos microrganismos que apresentam capacidade em degradar este composto (Ariole \& Abubakar, 2015). Desta forma o processo de biodegradação pode ser feito por um consórcio de microrganismos, tanto aeróbios como anaeróbios (utilizando diferentes receptores de elétrons) (Adrian \& Suflita, 1990; Aharon \& Fu, 2000; Almeida \& Guimarães, 2017).

Com o aumento da profundidade do solo, ocorre uma diminuição da concentração de oxigênio resultando em diferentes potenciais de oxirredução o que que favorece o metabolismo de diferentes grupos de microrganismos (anaeróbios redutores de nitrato, de ferro, de sulfato e metanogênicas) (Kolekar et al., 2014; Cecilia \& Maggi, 2016; Queiroz, B. P. V.; Monteiro, 2000; Vail et al., 2014).

Sabe-se que a degradação aeróbia da atrazina, que ocorre nas regiões mais aeradas do solo, é favorecida, uma vez que com o aumento da profundidade do solo, e consequentemente a formação de zonas anaeróbias, essa degradação tende a diminuir, em função de características cinéticas e termodinâmicas dos processos anaeróbios (Cecilia \& Maggi, 2016; Tuovinen et al., 2015). Assim, estudos mais aprofundados sobre as relações e processos aeróbios e anaeróbios associados a degradação da atrazina são importantes para a ampliação do potencial biotecnológico de lidar com os seus impactos ambientais. 


\subsection{Biodegradação aeróbia da atrazina}

Os processos aeróbios consistem no uso de um doador de elétrons em que o receptor final de elétrons é o oxigênio, e o processo se completa com a geração de dióxido de carbono (estado mais oxidado do carbono) e água. Nos processos metabólicos durante catabolismo microbiano ocorre a degradação de compostos orgânicos utilizados como fonte de carbono (doador de elétrons), e durante o anabolismo ocorre a produção de biomassa. Dentre os microrganismos aeróbios degradadores de atrazina destacam-se os gêneros Azospirillum, Pseudomonas, Alcaligenes, Enterobacter, Proteus, Klebsiella, Serratia, Bacillus, Arthrobacter, Streptomyces, Nocardia (Tomassoni et al., 2014).

Os microrganismos nas camadas mais profundas de solo são menos abundantes do que nas camadas superficiais, e são desfavorecidos pelos parâmetros cinéticos dos processos anaeróbios (Vail et al., 2014). Entretanto a atrazina pode estar presente em várias camadas de solo. Em camadas entre 0-90 cm de solo já verificou-se a atividade de degradação da atrazina predominante em condições aeróbias, com degradação média de $75 \%(0-15 \mathrm{~cm})$ sobre $65 \%$ nas camadas profundas $(0,75-90$ $\mathrm{cm}$ ) para uma concentração inicial de $0,123 \mu \mathrm{mol}$ (Tuovinen et al., 2015).

Em estudo com Rhodococcus sp, isolada de solo contaminado com Atrazina, Kolekar et al., (2014) relataram 75\% de degradação da Atrazina na concentração de $30 \mathrm{mg} / \mathrm{L}$. Ensifer $s p$. apresentou eficiência média de degradação: $54,3 \%$ a $25^{\circ} \mathrm{C}$, 99,7\% a $30^{\circ} \mathrm{C}$ e $84,7 \%$ a $35^{\circ} \mathrm{C}$,) e é ideal sob condições neutras a ácidas (pH 5, 91,5\%; pH 7, 99,7\%; pH 9, 91,7\%), bem como baixas velocidades de agitação (100 rpm (99,4\%) e 180 rpm (99,71\%) Verificou-se também que a eficiência de degradação da atrazina com base na temperatura, sendo a degradação da atrazina a $30^{\circ} \mathrm{C}$ melhor do que a $25^{\circ} \mathrm{C}$ e $35^{\circ} \mathrm{C}$. (Ma et al., 2017).

A degradação da atrazina também já foi estudada em biofiltros, em que a biodegradação pelo biofilme ligado à um tecido de fibras de vidro e à folha de PET têxtil atingiu 100\% em 6 horas, enquanto a biodegradação pelo biofilme ligado a cinza de carvão chegou a $69 \pm 4 \%$ em 8 horas (Swissa et al., 2015). Após 48h de incubação, para $1000 \mathrm{mg} / \mathrm{L}$ de atrazina utilizada como fonte de carbono, foi detectado $80 \%$ degradação deste composto pela ação de Rhodococcus sp que foram isolados à $30^{\circ} \mathrm{C}$ (Fazlurrahman et al., 2009). Embora a atrazina apresente alto potencial de degradação em condições aeróbias, este composto pode ser facilmente lixiviado para camadas mais profundas de solo, dependendo assim, da atividade metabólica de microrganismos anaeróbios para o seu processo de biodegradação. A seguir abordar-se-á os aspectos envolvidos na biodegradação anaeróbia da atrazina.

\subsection{Biodegradação anaeróbia da atrazina}

A biodegradação anaeróbia é um processo que resulta na transformação de constituintes orgânicos biodegradáveis em moléculas mais simples, como metano $\left(\mathrm{CH}_{4}\right)$ e dióxido de carbono $\left(\mathrm{CO}_{2}\right)$, além de subprodutos em solução aquosa, como amônia, sulfetos e fosfatos (FEIJOO et al., 2018). Este processo é realizado por uma diversidade de microrganismos, em reações bioquímicas sequenciais conhecidas como: hidrólise, acidogênese, acetogênese e metanogênese (D J Batstone et al., 2002; Bouallagui et al., 2005; Yen \& Brune, 2007).

O processo de biodegradação anaeróbia da atrazina, apresenta comportamento cinético inferior ao das condições aeróbias, entretanto, esse processo não é impedido nas camadas mais profundas de solo, e pode ocorrer através do uso de diferentes receptores de elétrons, como o dióxido de carbono $\left(\mathrm{CO}_{2}\right)$, nitrato $\left(\mathrm{NO}_{3}{ }^{-}\right)$e sulfato $\left(\mathrm{SO}_{4}{ }^{2-}\right)$ (Douglass et al., 2014; Freeman \& Thanki, 2017).

A biotransformação da atrazina foi afetada pelas condições redox de um solo contaminado, coletado de um riacho próximo à um plantio de cana-de-açúcar sob o uso de atrazina nas planícies do rio Mississipi, em que a taxa de biotransformação da atrazina foi extremamente rápida no solo oxidado. A concentração de atrazina caiu de aproximadamente $70 \mu \mathrm{g} / \mathrm{g}$ de solo para níveis não detectáveis após duas semanas de incubação, enquanto que a biotransformação da atrazina foi consideravelmente mais lenta nos solos mantidos sob condições anaeróbias, variando de uma concentração inicial de atrazina 
de $70 \mu \mathrm{g} / \mathrm{g}$ de solo para $9 \mu \mathrm{g} / \mathrm{g}$ atrazina após 99 dias, o que destaca uma degradação mais favorável em condições aeróbias (Delaune et al., 1997).

Estudos mais recentes mostram a resistência de degradação da atrazina em zonas anaeróbias. Um trabalho realizado por Bertelkamp (2018) não verificou a degradação deste herbicida em condições mais reduzidas (Bertelkamp et al., 2018). Todavia, a degradação anaeróbia da atrazina $(100 \mathrm{mg} / \mathrm{L})$ já foi verificada a $35^{\circ} \mathrm{C}$ por Pseudomonas sp. $(82,67 \%)$ seguida por Bacillus sp. (75,33\%) e Micrococcus sp. $(69,33 \%)$ ao final de 30 dias com amostras de águas lóticas contaminadas com o herbicida utilizado como única fonte de carbono e nitrogênio (Ariole \& Abubakar, 2015).

$\mathrm{O}$ uso da atrazina como fonte de nitrogênio já foi reportado em trabalho realizado na Nova Zelândia, em que os autores isolaram Arthrobacter nicotinovorans do solo contaminado com atrazina mantendo as condições de cultivo a $25^{\circ} \mathrm{C}$, suplementação com citrato de sódio como fonte de carbono e $1000 \mathrm{mg} / \mathrm{L}$ de atrazina como fonte de nitrogênio. Os autores observaram a degradação de 45,9\% da atrazina em 6 meses (Aislabie et al., 2018).

Os microrganismos envolvidos na biodegradação da atrazina em condições anaeróbias podem utilizar este composto como fonte de carbono/ doador de elétrons no seu processo de respiração anaeróbia, e diferentes compostos inorgânicos podem ser utilizados como receptores de elétrons, dentre os quais destacam-se os que serão discutidos nos próximos tópicos: nitrato, sulfato e dióxido de carbono.

\subsection{Desnitrificação}

Sobre condições de redução de nitrato, os microrganismos utilizam o nitrato $\left(\mathrm{NO}_{3}{ }^{-}\right)$como receptor de elétrons para a degradação da atrazina. Primeiramente o nitrato $\left(\mathrm{NO}_{3}{ }^{-}\right)$é reduzido a nitrito $\left(\mathrm{NO}_{2}{ }^{-}\right)$, e o processo se completa com a desnitrificação até nitrogênio gasoso $\left(\mathrm{N}_{2}\right)$, passando ainda pelas formas de $\mathrm{NO}$ e $\mathrm{N}_{2} \mathrm{O}$, antes de atingir a forma inerte (Z. Chen et al., 2016).

O contexto histórico de estudos sobre a degradação da atrazina em condições de redução de nitrato já observaram fenômenos de desalogenação hidrolítica da atrazina, sendo convertida a hidroxilado que é degradado mais facilmente em regiões submersas sob atmosfera de $\mathrm{N}_{2}$ (Adrian \& Suflita, 1990). Esses processos são mediados por consórcios bacterianos, e podem ser verificados pela liberação de $\mathrm{N}_{2}$ pelo processo de desnitrificação, envolvendo a formação de intermediários metabólicos como a hydroxyatrazina. (Mandelbaum et al., 1993)

Quanto às condições de $\mathrm{pH}$ e temperatura em meios de redução de nitrato, faixas de $\mathrm{pH}$ entre 5,5 e 8,5 se mostraram favoráveis ao processo de degradação, enquanto que temperaturas abaixo de $7^{\circ} \mathrm{C}$ limitam a degradação (Mandelbaum et al., 1993) e temperaturas mais elevadas entre $15-30^{\circ} \mathrm{C}$ favorecem a cinética microbiana, em que já foi observada a biodegradação da atrazina $(100 \mathrm{mg} / \mathrm{L})$ por Clostridium michiganese após 4 dias de incubação, utilizando a atrazina como fonte de carbono e nitrogênio (Mandelbaum et al., 1993).

\subsection{Sulfetogênese}

O enxofre, assim como o nitrogênio é um nutriente essencial à vida, e pode apresentar-se na natureza através de sulfetos metálicos, gesso $\left(\mathrm{CaSO}_{4}\right)$ e depósitos de enxofre elementar (Dennis, 2015; Lin et al., 2017). É responsável pela mineralização de $50 \%$ das moléculas de carbono em sedimentos marinhos, atuando como doador de elétrons em processos aeróbios ou como receptor de elétrons em condições anaeróbias (Bowles et al., 2014). Entretanto, poucos trabalhos abordam sobre a degradação da atrazina em condições de redução de sulfato. Todavia o sulfato $\left(\mathrm{SO}_{4}{ }^{2-}\right)$, que é a forma mais oxidada do enxofre, também pode ser utilizado como receptor de elétrons nos processos anaeróbios, enquanto que na sua forma $\mathrm{S}^{2}$ encontra-se no seu estado mais reduzido, destacando-se, portanto, como um possível doador de elétrons (Cao et al., 2014; Qian et al., 2017). 
A redução de sulfato $\left(\mathrm{SO}_{4}{ }^{2-}\right)$ ocorre através da ação de bactérias redutoras de sulfato (BRS) que utilizam o $\mathrm{SO}_{4}{ }^{2-}$ como receptor de elétrons (Cao et al., 2014; Dang \& Lovell, 2016; Pous et al., 2018; Qian et al., 2017). Ocorrendo o processo de redução de sulfato, pode haver formação de sulfetos, que deixam o meio com uma coloração escura.

Quando submetida a estas condições, a atrazina pode ser metabolizada pelas BRS como doadora de elétrons para os processos anaeróbios que envolvem a redução de sulfato, sofrendo degradação até atingir formas menos impactantes aos sistemas naturais, entretanto não são encontrados trabalhos recentes que avaliem a degradação da atrazina sobre estas condições de oxirredução, com exceção do artigo de Matias et al. (2019) que avalia a degradação da atrazina em diferentes condições de oxirredução, apontando ocorrência degradação sobre condições sulfetogênicas. Deursen (2016) estudou a degradação de outros pesticidas sobre essa condição de oxirredução e destaca que este é um processo lento, e que sobre estas condições a degradação de pesticidas (2,4,D, BAM, MCPP) foi praticamente insignificante. (Freeman \& Thanki, 2017; Hardison et al., 2015).

\subsection{Metanogênese}

O processo metanogênico é realizado através de um grupo muito especializado de microrganismos, as arquéias metanogênicas, que apresentam maior sensibilidade a choques orgânicos do que as bactérias que participam das etapas anteriores dos processos anaeróbios: hidrólise, acidogênese e acetogênese (Vilcáez, 2017; Wang et al., 2015). Esta etapa consiste na conversão de acetato e $\mathrm{H}_{2}$ em metano $\left(\mathrm{CH}_{4}\right)$ e dióxido de carbono $\left(\mathrm{CO}_{2}\right)$ (Wilkie et al., 1986). As arquéias utilizam um número limitado de substratos: acetato, $\mathrm{H}_{2} / \mathrm{CO}_{2}$, fórmico, metanol e metilaminas (Yamada et al., 2014b). E para o equilíbrio deste processo é necessário baixas pressões de $\mathrm{H}_{2}$ (Yamada et al., 2014a).

Sobre condições metanogênicas o processo de biodegradação implica na formação de metano $\left(\mathrm{CH}_{4}\right)$, e os microrganismos envolvidos utilizam dióxido de carbono $\left(\mathrm{CO}_{2}\right)$ dissolvido no líquido como receptor de elétrons para a degradação da atrazina. Em condições metanogênicas já verificou-se maior recalcitrância da atrazina à biodegradação (Gu et al., 2003). A operação de reatores anaeróbios exige condições operacionais e ambientais que favoreçam a atividade metanogênica, tendo em vista que o objetivo principal desse processo é a degradação do herbicida atrazina (Damien et al., 2015).

\subsection{Intermediários metabólitos da atrazina}

A busca por melhores resultados nas taxas de degradação da atrazina vem sendo estudados com mais ênfase a partir da década de 90, em que estudos sobre a atividade microbiana acerca deste micropoluente destacam que processos combinados de degradação aeróbia e anaeróbia apresentam maior eficiência nos ambientes naturais, pois a atrazina pode ser lixiviada de uma camada aeróbia para camadas mais profundas, em condições anaeróbias, sendo submetida a uma série de processos físicoquímicos paralelos a degradação biológica (Behki et al., 1993; M. L. D. E. Souza et al., 1998).

São poucos os microrganismos capazes de mineralizar completamente a atrazina. Entretanto, a degradação da atrazina já foi observada pela ação de Pseudomonas sp. (87\% p/ 100 mg/L de atz) (Cecilia \& Maggi, 2016; Vail et al., 2014), e de Rhodococcus sp. utilizando a atrazina como fonte de carbono e energia, com geração de intermediários menos tóxicos como o $\mathrm{N}$-isopropylammilide (Kolekar et al., 2014).

Outros metabólitos da degradação da atrazina foram identificados por cromatografia em camada delgada. Foram observados, nas frações dessorvidas, hidroxiatrazina (44\%), desisopropilatrazina $(3,28 \%)$ e atrazina $(52,72 \%)$ e nas frações extraídas, hidroxiatrazina $(16,22 \%)$, desisopropilatrazina $(2,25 \%)$, desetilatrazina $(2,24 \%)$ e atrazina $(79,29 \%)$ (QUEIROZ, B. P. V.; MONTEIRO, 2000). E os mesmos autores frisam que a mineralização da atrazina foi beneficiada pela alternância de temperatura $\left(25^{\circ} \mathrm{C} \pm 5^{\circ} \mathrm{C}\right)$ de dias e noites durante o período de 150 dias de incubação. 
Usando espécies de levedura a degradação da atrazina chegou a 100\% em 9 dias pela ação de C. laurentii em que as melhores condições de crescimento foram encontradas em pH 7, 30 ${ }^{\circ} \mathrm{C}$ e $120 \mathrm{rpm}$, para $150 \mathrm{mg} / \mathrm{L}$ de atrazina (Abigail et al., 2012). Por meio de análise por GC-MS Estes mesmos autores detectaram a formação de quatro metabolitos oriundos da degradação da atrazina por meio de GC-MS: hidroxitrazina, deetilatrazina, deisopropilpirazina e deetildeisopropilatrazina durante o processo de degradação da atrazina. As interações entre os elementos bióticos e abióticos do solo com a atrazina formam intermediários como hidroxiatrazina, deetilatrazina, deisopropilatrazina, nisopropilammilida, $\mathrm{N}$-etilaminilida e ácido cianúrico. (Kolekar et al., 2014). Frisa-se que muitos intermediários metabólitos da atrazina podem ser ainda mais tóxicos do que o próprio herbicida, o que ressalta a importância do controle das plumas de propagação deste i.a. no solo e em águas superficiais e subterrâneas (Matias et al., 2019).

\subsection{Consórcios microbianos}

A mineralização da atrazina não ocorre pela ação exclusiva de uma espécie microbiana, este processo necessita de diversidade biológica, com a participação de microrganismos aeróbios e anaeróbios. Os consórcios microbianos de degradação da atrazina em ambientes aeróbios e anaeróbios foram observados por trabalhos que encontraram organismos do gênero Pseudomonas sp., Rhodococus sp., Rhizobium, Escherichia coli., Nocardia sp. (Giardi et al., 2014; M. L. D. E. Souza et al., 1995; Yanze-kontchou \& Gschwind, 1994).

A degradação da atrazina por microrganismos anaeróbios de cultura mista também já foi confirmada no processo cometabolico, com concentrações de atrazina de $15 \mathrm{mg} / \mathrm{L}$ chegando até 95\% de degradação (Kumar \& Philip, 2004). Outros estudos também mostram que a biodegradação da atrazina pode ser promovida em solos insaturados, por meio de técnicas de bioaumentação, favorecidas pelas interações naturais da diversidade microbiana presente no solo contaminado (Jenkins, 2015).

Outros trabalhos destacam espécies como Acinetobacter spp., Aerobacterium sp., Microbacterium sp., Bacillus sp., Micrococcus sp., Deinococcus sp., e Delftia acidovorans, bem como consórcios de espécies Agrobacterium tumefaciens, Caulobacter crescentus, Pseudomonas putida, Sphingomonas yaniokuyae, Nocardia sp., Rhizobium sp., Flavobacterium oryzihabitans e Variovorax paradoxos em ambientes contaminados com atrazina (Batstone et al., 2002; Behki et al., 1993; Boe et al., 2017; Chen et al., 2016; Javaroni et al., 2016; Jenkins, 2015; Kumar \& Philip, 2004; Neiverth, 2015; Oliveira, 2013), e estes microrganismos apresentam potencial de degradação da atrazina por meio de seus processos metabólicos, principalmente Pseudomonas sp., que atingem valores mais altos de degradação, em torno de 80 a $90 \%$ (100mg/L de atrazina) em condições mesofílicas, (Ariole \& Abubakar, 2015).

Em trabalhos abordando diferentes tipos de manejo de solos contaminados com atrazina, foram encontrados 56 gêneros de bactérias e arqueias com potencial para degradação do herbicida atrazina, divididos em 178 espécies e destas, 43 foram comuns a todos os tipos de manejos e 135 espécies diferentes entre os solos, dentre as quais destacam-se as que foram citadas no parágrafo anterior (Campanari, 2017). Das pesquisas citadas destaca-se que a diversidade microbiana e as suas interrelações, configurando consórcios microbianos, estão evidenciados e vinculados ao processo biodegradação da atrazina, o que é fundamental para a implementação de projetos de biorremediação.

\subsection{Enzimas envolvidas no processo de biodegradação da atrazina}

A biodegradação da atrazina também pode ocorrer pela ação enzimática, que baseia-se na ação de um catalisador biológico sobre o herbicida. As enzimas redox ou oxiredutases catalisam as reações de oxirredução, e estão incluídas nessa classe as hidrogenases, oxidases, peroxidases e hidroxilases (Balesteros, 2009). Os produtos dos genes atzA, atzB, atzC são responsáveis pela remoção do cloro e dos resíduos de isopropilamina e etilamina para produzir ácido cianúrico, que é convertido a $\mathrm{NH}_{3}$ e $\mathrm{CO}_{2}$ pela ação das enzimas decodificadas pelos genes atzD, atzE e atzF (Fernades, 2014).

A proteína relativa ao gene trzD é um análogo metabolizador considerado mais eficiente na metabolização da atrazina, 
por meio de uma rápida conversão em ácido cianúrico catabolizante na primeira parte da via de degradação. Outro gene que participa da degradação da atrazina é o gene trzN, que é considerado parte da família das amidohidrolases atuando na degradação da atrazina, possuindo, entretanto, uma diversidade mais ampla de substratos. Por esse motivo, estima-se que este gene está se tornando mais disperso em relação ao gene atzA (Accepts et al., 2014; Campanari, 2017). A Tabela 2 sintetiza os genes que expressam enzimas envolvidas na degradação da atrazina e as suas respectivas proteínas e funções.

Reconhecer as etapas, funções e reações associadas as enzimas que atuam no processo de biodegradação da atrazina é fundamental para a busca de alternativas que viabilizem a catalização do processo por meio de ferramentas e técnicas de biologia molecular e biotecnologia, especialmente para o planejamento e operação de reatores biológicos de funcionamento aeróbio ou anaeróbio. Desta forma, a Tabela 2 é uma importante indicação sobre as principais etapas associadas às funções dos genes que expressam enzimas, podendo ser utilizada para a tomada de decisão sobre medidas operacionais de reatores biológicos.

Frisa-se que o conhecimento sobre estas enzimas, assim como a relação com a diversidade microbiana e os processos bioquímicos envolvidos no processo de degradação da atrazina e de outros agrotóxicos, são de fundamental importância para o desenvolvimento de tecnologias que busquem a degradação destes compostos químicos, visando a redução dos impactos ambientais e danos à saúde humana que podem ser causados por estas substâncias.

Tabela 2. Resumo funcional de cada gene (Banco de dados uniprot/adaptado).

\begin{tabular}{|c|c|c|}
\hline \multicolumn{3}{|c|}{ Funções dos genes que expressam enzimas na biodegradação da atrazina } \\
\hline Gene & Proteína & Função \\
\hline atzA & Atrazina clorohidrolase & Desclorinação da atrazina para HA \\
\hline atzB & Hidroxidecloroatrazina etilaminohidrolase & $\begin{array}{c}\text { Catalisador da reação de desaminação de HA para N- } \\
\text { isopropilamelida }\end{array}$ \\
\hline atzC & $\mathrm{N}$-isopropilamelida isopropilamidohidrolase & $\begin{array}{c}\text { Conversão de N-isopropilamelida para ácido cianúrico e } \\
\text { isopropilamina }\end{array}$ \\
\hline atzE & Biureto hidrolase & Hidrolisa biureto em alofanato e amônia \\
\hline atzF & Alofanato hidrolase & Hidrolisa alofanato em amônia e gás carbônico \\
\hline ipuC & Glutamato-isopropilaminaligase & $\begin{array}{c}\text { Envolvida na degradação de isopropilamina, constituinte da } \\
\text { atrazina }\end{array}$ \\
\hline ipuF & $\begin{array}{l}\text { Gama-glutamil-L-1-hidroxiisopropilamida } \\
\text { hidrolase }\end{array}$ & Envolvida na degradação de isopropilamina \\
\hline $\operatorname{tch} E$ & $\begin{array}{c}\text { Metanol:N,N-dimetil-4-nitrosoanilina } \\
\text { oxidoredutase }\end{array}$ & Catalisa a oxidação de metanol e formação de formaldeído \\
\hline triA & Melamina deaminase & $\begin{array}{l}\text { Desloca agrupamentos amina de melamina e } \\
\text { aminoatrazina. }\end{array}$ \\
\hline $\operatorname{trzD}$ & Amidohidrolase de ácido cianúrico & $\begin{array}{c}\text { Cliva o anel s-triazina e ácido cianúrico, produzindo } \\
\text { dióxido de carbono e biureto. }\end{array}$ \\
\hline gatA & Biuretohidrolase e amidase (predita) & Mesma função de atzE \\
\hline
\end{tabular}

Fonte: Adaptado: Banco de dados uniprot, (2018).

O conhecimento de dados qualitativos e quantitativos da biodegradação da atrazina, que contempla os processos aeróbios, anaeróbios e enzimáticos, pode auxiliar na tomada de decisões regulatórias, no aumento da fiscalização do produto 
agrícola cujo uso está em alta e na autorização de estudos e pesquisas para registro de alternativas menos impactantes para lidar com problema. A análise de dados referentes a estas substâncias também permite um maior embasamento para estudos de contaminação nas águas superficiais e subterrâneas e de efeitos adversos à fauna e a flora (Chiarello et al., 2016). É importante que mais estudos sobre as diferentes rotas de degradação da atrazina sejam realizados, para buscar métodos de tratamento biológico, visando manter a qualidade dos solos e das águas subterrâneas expostos a este herbicida.

\section{Considerações Finais}

Existem evidências de que, em função de suas características e comportamento ambiental, a atrazina é um composto capaz de trazer danos à saúde e ao meio ambiente, merecendo atenção e cuidados especiais voltados ao seu uso e aplicação no setor agrícola, com atenção às regulamentações de concentração e disposição da atrazina no solo, considerando o seu potencial de contaminar águas subterrâneas e superficiais. Neste sentido, é fundamental que o poder público se atente às questões sobre a liberação de agroquímicos com riscos ambientais e para a saúde acentuados, como é o caso da atrazina.

A biodegradação é uma alternativa eficiente na remoção da atrazina dos ambientes naturais, que pode utilizar os microrganismos nativos do próprio ambiente contaminado para realizar este processo, que se dá por meio de reações bioquímicas sequenciais regidas por consórcios microbianos. A obtenção de informações sobre os processos de biodegradação da atrazina em diferentes condições de oxirredução pode ser utilizada para a tomada de decisão em projetos ambientais que visem a mineralização deste composto, ou, ao menos a sua degradação em intermediários metabólicos menos tóxicos, visando a proteção do solo, das águas superficiais e subterrâneas, bem como da saúde pública. Além disso, foi possível verificar que a biodegradação da atrazina é favorecida em condições aeróbias, podendo ocorrer em anaerobiose, embora com menor eficiência.

Considerando as propriedades de solubilidade da atrazina e potencial de lixiviação para camadas mais profundas de solo, são necessários estudos que discorram sobre a degradação biológica da atrazina em ambiente anaeróbio, haja vista a escassez de trabalhos nessas condições, principalmente envolvendo condições metanogênicas e sulfetogênicas. Em função da complexidade molecular da atrazina, ela sofre degradação biológica apenas pela ação de consórcios microbianos e uma ampla diversidade enzimática, que deve ser mais explorada para a obtenção de informações relevantes para lidar com o problema de áreas contaminadas com atrazina. Desta forma sugere-se como trabalhos futuros, a realização de pesquisas específicas sobre a biodegradação da atrazina em diferentes condições de oxirredução, tipos de solos e condições operacionais, como temperatura, pH e matéria orgânica.

\section{Agradecimentos}

Agradecemos ao Programa de Pós-Graduação em Ciências Ambientais (PPGCA) da Universidade Federal de Alfenas (UNIFAL-MG), a ITAIPU BINACIONAL e a Fundação Parque Tecnológico de Itaipu (FPTI) pelo financiamento da pesquisa. Agradecemos também toda a equipe de ITAIPU, especialmente a Simone Frederigi Benassi. O presente trabalho foi realizado com apoio da Coordenação de Aperfeiçoamento de Pessoal de Nível Superior (CAPES) - Código de Financiamento 001.

\section{Referências}

Abigail, E. A., Lakshimi, V., \& Das, N. (2012). Biodegradation of atrazine by Cryptococcus laurentii isolated from contaminated agricultural soil. Journal of Microbiology and Biotechnology Research, 2(3), 450-457.

Accepts, A. E. M., Society, A., \& Reserved, A. R. (2014). Growth of anaerobic methane oxidizing archea and sulfate reducing bacteria in a hight pressure membrane-capsule bioreactor. Applied and Environmental Microbiology, December. https://doi.org/10.1128/AEM.03255-14 
Adrian, N. R., \& Suflita, J. M. (1990). Reductive Dehalogenation of a Nitrogen Heterocyclic Herbicide in Anoxic Aquifer Slurries. Applied and Environmental Microbiology, 292-294.

Aharon, P., \& Fu, B. (2000). Microbial sulfate reduction rates and sulfur and oxygen isotope fractionations at oil and gas seeps in deepwater Gulf of Mexico. Geochimica et Cosmochimica, 64(2), 233-246.

Aislabie, J., Bej, A. K., Ryburn, J., Lloyd, N., \& Wilkins, A. (2018). Characterization of Arthrobacter nicotinovorans HIM , an atrazine-degrading bacterium , from agricultural soil New Zealand. FEMS Microbiology Ecology, 52(August), 279-286. https://doi.org/10.1016/j.femsec.2004.11.012

Almeida, L. da S., \& Guimarães, E. C. (2017). Space distribution of the ctc and the relationship macronutrients in a red-yellow latosol cultivated with coffee. Agronomic Culture, 625-639.

Amaro, B. B. D. F., Correia, D. B., Freitas, R. A., Teixeira, P. H. R., Nascimento, C. A., Pereira, C. M., Silva, J. R. L., Silva, M. S. A., Cruz, G. V., Queiroz, M. B., Oliveira, J. P. C., Silva, R. A. R., Macedo, G. F. \& Kamdem, J. P. (2021). A Biossegurança no uso de agrotóxicos na percepção de agricultores do Distrito de Cuncas, Barro - Ceará: Saúde Física e Ambiental. Research, Society and Development, 10(1), e15610111644. https://doi.org/10.33448/rsdv10i1.11644

Ariole, C. N., \& Abubakar, A. (2015). Biodegradation of Atrazine by Bacteria Isolated from Lotic Water. Journal of Applied Life Sciences International, 2(3), 119-125. https://doi.org/10.9734/JALSI/2015/14345

Balesteros, M. R. (2009). Development and optimization of methodology for the analysis of atrazine and its degradation products by high performance liquid chromatography and capillary electrophoresis.

Batstone, D J, Keller, J., Angelidaki, I., Kalyuzhnyi, S. V, Pavlostathis, S. G., \& Rozzi, A. (2002). The IWA Anaerobic Digestion Model No 1 ( ADM1 ). Water Science and Technology, 1(1), 65-74.

Batstone, Damien J., Lu, Y., \& Jensen, P. D. (2015). Impact of dewatering technologies on specific methanogenic activity. Water Research, 82(October), 7885. https://doi.org/10.1016/j.watres.2015.04.005

Behki, R., Topp, E., Dick, W., \& Germon, P. (1993). Metabolism of the Herbicide Atrazine by Rhodococcus Strainst. Applied and Environmental Microbiology, 59(6), 1955-1959.

Bertelkamp, C., Verliefde, A. R. D., Schoutteten, K., Vanhaecke, L., Bussche, J. Vanden, Singhal, N., \& Hoek, J. P. Van Der. (2018). The effect of redox conditions and adaptation time on organic micropollutant removal during river bank filtration: A laboratory-scale column study Science of the Total Environment The effect of redox conditions and adaptation time on organic micropolluta. Science of the Total Environment, 544(February 2016), 309-318. https://doi.org/10.1016/j.scitotenv.2015.11.035

Berticelli, R., Decesaro, A., Magro, F., \& Colla, L. M. (2016). Compostagem Como Alternativa De Biorremediação De Áreas Contaminadas. Revista CIATEC $-U P F, 8(1), 12-28$.

Boe, K., John, D., Steyer, J., \& Angelidaki, I. (2017). State indicators for monitoring the anaerobic digestion process. Water Research, 44(20), 5973-5980. https://doi.org/10.1016/j.watres.2010.07.043

Bonfleur, E. J. (2010). Behavior of the association between the herbicides glyphosate and atrazine in a dark red Latosol of the Brazilian cerrado biome (pp. $1-81)$.

Bouallagui, H., Touhami, Y., Cheikh, R. Ben, \& Hamdi, M. (2005). Bioreactor performance in anaerobic digestion of fruit and vegetable wastes. Process Biochemistry, 40, 989-995. https://doi.org/10.1016/j.procbio.2004.03.007

Bowles, M. W., Mogollón, J. M., Kasten, S., Zabel, M., \& Hinrichs, K.-U. (2014). Global Rates of Marine Sulfate Reduction and Implications for Sub - SeaFloor Metabolic Activities. Sciencexpress, May, 1-7. https://doi.org/10.1038/35351

Brand, A. R., Ant, D., Nas, R., Ramalho, A., Pereira ${ }^{1}$, B., Antônio, D., \& De Freitas'1 F. F. (2012). Use of Microorganisms for Bioremediation of Impacted Environments. Rev. Elet. Em Gestão Educação e Tecnologia Ambiental, 6(6), 975-1006. www.ufsm.br/reget\%5Cnhttp://cascavel.ufsm.br/revistas/ojs2.2.2/index.php/reget

Campanari, M. F. Z. (2017). Metagenomics of Atrazine Degradation in Soil Under Different Agricultural and Semidecidual Forest Management (pp. 1-76). Cao, H., Wang, Y., Lee, O. on, Zeng, X., Shao, Z., \& Qian, P.-Y. (2014). Microbial Sulfur Cycle in Two Hydrothermal Chimneys on the. Mbio, 5(1), 1-11. https://doi.org/10.1128/mBio.00980-13.Editor

Chen, Y., Cheng, J. J., \& Creamer, K. S. (2008). Inhibition of anaerobic digestion process: A review. Bioresource Technology, 99(10), 4044-4064. https://doi.org/10.1016/j.biortech.2007.01.057

Chen, Z., Wang, C., Gschwendtner, S., \& Willibald, G. (2016). Denitrification nitrogen gas formation and gene expression in alpine grassland soil as affected by climate change conditions Soil Biology \& Biochemistry Relationships between denitri fi cation gene expression, dissimilatory nitrate reduction to ammonium . Soil Biology and Biochemistry, 87(April 2013), 67-77. https://doi.org/10.1016/j.soilbio.2015.03.030

Chiarello, M., Graeff, R., Minetto, L., Cemin, G., Schneider, V. E., Moura, S., Chiarello, M., Graeff, R. N., Minetto, L., Cemin, G., Schneider, V. E., \& Moura, S. (2016). Determination of pesticides in water and sediments by HPLC-HRMS and their relation with the use and occupation of soil. New Chemistry, 40(2), 158-165. https://doi.org/10.21577/0100-4042.20160180

CONAMA 357. (2005). Resolução n. 58-63.

Dang, H., \& Lovell, C. R. (2016). Microbial Surface Colonization and Biofilm Development in Marine Environments. Microbiology and Molecular Biology Reviews, 80(1), 91-138. https://doi.org/10.1128/MMBR.00037-15.Address 
Delaune, R. D., Devai, I., Mulbah, C., Crozier, C., \& Lindau, C. W. (1997). The influence of soil redox conditions on atrazine degradation in wetlands. Agriculture, Ecosystems \& Environment, 66(1), 1-87.

Dellamatrice, P. M., \& Monteiro, R. T. (2014). Principais aspectos da poluição de rios brasileiros por pesticidas. Brazilian Journal of Agricultural and Environmental Engineering, July 2015. https://doi.org/10.1590/1807-1929/agriambi.v18n12p1296-1301

Dennis, K. E. (2015). Using the Sulfur Cycle to Constrain Changes in Seawater Chemistry During the Paleogene. Syracuse University Surface.

Douglass, J. F., Radosevich, M., \& Tuovinen, O. H. (2014). Mineralization of atrazine in the river water intake and sediments of a constructed flow-through wetland. Ecological Engineering, 72(August 2015), 35-39. https://doi.org/10.1016/j.ecoleng.2014.08.016

Fazlurrahman, Batra, M., Pandey, J., Suri, C. R., \& Jain, R. K. (2009). Isolation and characterization of an atrazine-degrading Rhodococcus sp . strain MB-P1 from contaminated soil. Letters in Applied Microbiology, 49, 721-729. https://doi.org/10.1111/j.1472-765X.2009.02724.X

Feijoo, G., Soto, M., Mendez, R. R., \& Lema, J. M. (2018). Sodium inhibition in the anaerobic digestion process : Antagonism and adaptation phenomena. Enzyme and Microbial Technology, June. https://doi.org/10.1016/0141-0229(94)00011-F

Fernades, A. F. T. (2014). Caracterização fenotípica e molecular de linhagens de Pseudomonas spp . envolvidas na biodegradação da atrazina Caracterização fenotípica e molecular de linhagens de Pseudomonas spp . envolvidas na biodegradação da atrazina.

Freeman, J., \& Thanki, D. (2017). Water contaminated with the herbicide atrazine. Journal of Purdue Undergraduate Research, 1, 57-64.

Furlan, RG; Martins, JF; Santos, JI; Alves, P. (2016). Simulation of the residual effect of atrazine on carrot. Horticultura Brasileira, 0, 584-587. https://doi.org/10.12741/ebrasilis.v7i1.371

Gargouri, B., Mhiri, N., Karray, F., Aloui, F., \& Sayadi, S. (2015). Isolation and Characterization of Hydrocarbon-Degrading Yeast Strains from Petroleum Contaminated Industrial Wastewater. BioMed Research International, 2015(SEPTEMBER), 1-11. https://doi.org/10.1155/2015/929424

Giardi, M. T., Giardina, M. C., \& Filacchioni, G. (2014). Chemical and Biological Degradation of Primary Metabolites of Atrazine bv a Nocardia Strain. Agricultural and Biological Chemistry, 1369. https://doi.org/10.1080/00021369.1985.10866949

Gu, J., Fan, Y., \& Gu, J. (2003). Biodegradability of Atrazine, Cyanazine and Dicamba under methanogenic condition in three soils of China. Chemosphere, 52, 1515-1521. https://doi.org/10.1016/S0045-6535(03)00490-9

Hardison, A. K., Algar, C. K., Giblin, A. E., \& Rich, J. J. (2015). ScienceDirect Influence of organic carbon and nitrate loading on partitioning between dissimilatory nitrate reduction to ammonium (DNRA) and $\mathrm{N} 2$ production. GEOCHIMICA ET COSMOCHIMICA ACTA, 164, 146-160. https://doi.org/10.1016/j.gca.2015.04.049

Hunter, W. J., \& Shaner, D. L. (2009). Nitrogen limited biobarriers remove atrazine from contaminated water : Laboratory studies. Journal of Contaminant Hydrology, 103(1-2), 29-37. https://doi.org/10.1016/j.jconhyd.2008.08.004

Javaroni, R. D. C. A., Landgraf, M. D., \& Rezende, M. O. O. (2016). Behavior of the herbicides atrazine and alachlor applied to soil prepared for the cultivation of sugarcane. New Chemistry, February 1999. https://doi.org/10.1590/S0100-40421999000100012

Jenkins, J. J. (2015). Atrazine degradation by bioaugmented sediment from constructed wetlands. Applied Microbiology and Biotechnology, February. https://doi.org/10.1007/s002530100792

Kabra, A. N., Ji, M. K., Choi, J., Kim, J. R., Govindwar, S. P., \& Jeon, B. H. (2014). Toxicity of atrazine and its bioaccumulation and biodegradation in a green microalga, Chlamydomonas mexicana. Environmental Science and Pollution Research, October, 12270-12278. https://doi.org/10.1007/s11356-014$3157-4$

Kanissery, R. G., \& Sims, G. K. (2011). Biostimulation for the Enhanced Degradation of Herbicides in Soil. Applied and Environmental Soil Science, 2011. https://doi.org/10.1155/2011/843450

Kolekar, P. D., Phugare, S. S., \& Jadhav, J. P. (2014). Biodegradation of atrazine by Rhodococcus sp. BCH2 to N-isopropylammelide with subsequent assessment of toxicity of biodegraded metabolites. Environmental Science and Pollution Research, 21(3), 2334-2345. https://doi.org/10.1007/s11356-0132151-6

Kumar, P., \& Philip, L. (2004). Atrazine degradation in anaerobic environment by a mixed microbial consortium. Water Research, 38, 2277-2284. https://doi.org/10.1016/j.watres.2003.10.059

Cecilia, D., \& Maggi, F. (2016). Kinetics of atrazine, deisopropylatrazine, and deethylatrazine soil biodecomposers. Journal of Environmental Management, 183(September), 673-686. https://doi.org/10.1016/j.jenvman.2016.09.012

Lin, Z., Sun, X., Strauss, H., Lu, Y., Xu, L., \& Lu, H. (2017). Sulfur isotopic evidence for the origin of elemental sulfur in gas hydrate-bearing sediments of the northern South China Sea. Geophysical Research Abstracts, 19(1993), 2502.

Ma, L., Chen, S., Yuan, J., Yang, P., Liu, Y., \& Stewart, K. (2017). Rapid biodegradation of atrazine by Ensifer sp. strain and its degradation genes. International Biodeterioration and Biodegradation, 116(November 2016), 133-140. https://doi.org/10.1016/j.ibiod.2016.10.022

Machado, C. S., Fregonesi, B. M., Zagui, G. S., Martinis, B. S. de, \& Segura-Muñoz, S. (2018). Atrazine in river water: human health risk assessment by recreational exposure. Environmental Management and Sustainability Journal, 7(2016), 36-46. https://doi.org/10.19177/rgsa.v7e3201836-46

Mandelbaum, R. T., Wackett, L. P., \& Allan, D. L. (1993). Mineralization of the s-Triazine Ring of Atrazine by Stable Bacterial Mixed Cultures. Applied and Environmental Microbiology, 59(6), 1695-1701. 
Matias, T. P., Braga, J. K. \& Brucha, G. (2019). Anaerobic biodegradation of atrazine under different redox conditions. International Journal of Advanced Engineering Research and Science, 6(10), 227-236. https://doi.org/10.22161/ijaers.610.35

Neiverth, C. A. (2015). Determination of atrazine in water using solid phase extraction and gas chromatography coupled to mass spectrometry. Ambiciência Guarapuava, 1, 475-482. https://doi.org/10.5935/ambiencia.2015.02.14nt

Oliveira, D. A. do C. A. P. B. do C. J. M. B. P. J. L. M. (2013). Comportamento ambiental e toxidade dos herbicidas atrazina e simazina. Revista Ambiente e Agua. https://doi.org/10.4136/1980-993X

Pacwa-Płociniczak, M., Płaza, G. A., Poliwoda, A., \& Piotrowska-Seget, Z. (2014). Characterization of hydrocarbon-degrading and biosurfactant-producing Pseudomonas sp. P-1 strain as a potential tool for bioremediation of petroleum-contaminated soil. Environmental Science and Pollution Research, 21(15), 9385-9395. https://doi.org/10.1007/s11356-014-2872-1

Pereira, A. S., Shitsuka, D. M., Parreira, F. J. \& Shitsuka, R. (2018). Método Qualitativo, Quantitativo ou Quali-Quanti. In Metodologia da Pesquisa Científica (1st ed.). UFSM, NTE. https://repositorio.ufsm.br/bitstream/handle/1/15824/Lic_Computacao_Metodologia-Pesquisa-Cientifica.pdf?sequence=1. Acesso em: 28 março 2020 .

Polonio, J. C., Polli, A. D., Bulla, L. M. C., Rosseto, P., Dos Santos, C. M., Rhoden, S. A., Pamphile, J. A., \& Conte, H. (2014). Potencial biorremediador de microrganismos: Levantamento de resíduos industriais e urbanos tratáveis no município de Maringá-PR. BBR - Biochemistry and Biotechnology Reports, 3(2), 31. https://doi.org/10.5433/2316-5200.2014v3n2p31

Pous, N., Balaguer, M. D., Colprim, J., \& Puig, S. (2018). Opportunities for groundwater microbial. Microbial Biotechnology. https://doi.org/10.1111/17517915.12866

Qian, J., Wang, L., Wu, Y., Bond, P. L., Zhang, Y., \& Chang, X. (2017). Free sulfurous acid (FSA) inhibition of biological thiosulfate reduction (BTR) in the sulfur cycle-driven wastewater treatment process. Chemosphere. https://doi.org/10.1016/j.chemosphere.2017.02.117

Queiroz, B. P. V.; Monteiro, R. T. R. (2000). Degradation of 14 c-atrazine in soil under semicontrolled conditions 1. SCIELO, 849-856.

Rajagopal, R., Massé, D. I., \& Singh, G. (2013). A Critical Review on Inhibition of Anaerobic Digestion Process by Excess Ammonia Bioresource Technology A critical review on inhibition of anaerobic digestion process by excess ammonia. Bioresource Technology, 143(February 2018), 632-641. https://doi.org/10.1016/j.biortech.2013.06.030

Rodr, D. M. (2015). Bioremediation of Petroleum Derivative Using Biosurfactant Produced by Serratia marcescens UCP / WFCC 1549 in Low-Cost Medium. 4(August), 550-562.

Sene, L., Converti, A., Aparecida, G., Secchi, R., \& Cássia, R. De. (2010). New Aspects on Atrazine Biodegradation. Brazilian Archives of Biology and Technology, 53(April), 487-496.

Silva, A. A. da. (2014). Bioprospecting of bacteria with atrazine degradation potential in sugarcane plantations in the state of Mato Grosso do Sul.

Souza, E. L. De, Damasceno, F., Schirmer, G. K., Ramires, M. F., Bisognin, R. P., Bohrer, R. E. G., Vasconcelos, M. D. C., \& Cezimbra, J. C. G. (2018). Resíduos contaminantes no solo: possibilidades e consequências. Journal of Environmental Management and Sustainability, 484-509. https://doi.org/10.19177/rgsa.v7e22018465-483

Souza, M. L. D. E., Newcombe, D., Alvey, S. A. M., Crowley, D. E., Hay, A., Sadowsky, M. J., \& Wackett, L. P. (1998). Molecular Basis of a Bacterial Consortium : Interspecies Catabolism of Atrazine. Applied and Environmental Microbiology, 64(1), 178-184.

Souza, M. L. D. E., Wackett, L. P., Boundy-mills, K. L., Mandelbaum, R. T., \& Sadowsky, M. J. (1995). Cloning, Characterization , and Expression of a Gene Region from Pseudomonas sp. Strain ADP Involved in the Dechlorination of Atrazine $\uparrow$. Applied and Environmental Microbiology, 61(9), 3373-3378.

Swissa, N., Nitzan, Y., Anker, Y., \& Cahan, R. (2015). Biofilter based on a biofilm immobilized on geo-textile sheets for rapid atrazine biodegradation. International Biodeterioration and Biodegradation, 105(October 2016), 146-152. https://doi.org/10.1016/j.ibiod.2015.09.002

Tomassoni, F., Santos, R. F., Santos, F. S., Carpinski, M., \& Silveira, L. da. (2014). Soil Bioremediation Technique. Actalguazu, 3(3), 46-56.

Tuovinen, O. H., Deshmukh, V., Ozkaya, B., \& Radosevich, M. (2015). Kinetics of aerobic and anaerobic biomineralization of atrazine in surface and subsurface agricultural soils in Ohio. Journal of Environmental Science and Health Part B-Pesticides Food Contaminants and Agricultural Wastes, 50(10), 718-726. https://doi.org/10.1080/03601234.2015.1048105

Vail, A. W., Wang, P., Uefuji, H., Samac, D. A., Vance, C. P., Wackett, L. P., \& Sadowsky, M. J. (2014). Biodegradation of atrazine by three transgenic grasses and alfalfa expressing a modified bacterial atrazine chlorohydrolase gene. Transgenic Research, 24(3), 475-488. https://doi.org/10.1007/s11248-0149851-7

Vilcáez, J. (2017). Numerical modeling and simulation of microbial methanogenesis in geological CO2 storage sites Journal of Petroleum Science and Engineering Numerical modeling and simulation of microbial methanogenesis in geological CO 2 storage sites. Journal of Petroleum Science and Engineering, 135(November 2015), 583-595. https://doi.org/10.1016/j.petrol.2015.10.015

Wang, D. T., Gruen, D. S., Lollar, B. S., Hinrichs, K., Stewart, L. C., Holden, J. F., Hristov, A. N., Pohlman, J. W., Morrill, P. L., Könneke, M., Delwiche, B., Reeves, E. P., Sutcliffe, C. N., Ritter, D. J., \& Seewald, J. S. (2015). Nonequilibrium clumped isotope signals in microbial methane 3. Science.

Wilkie, A., Goto, M., Bordeaux, F. M., \& Smith, P. H. (1986). Enhancement of Anaerobic Methanogenesis from Napiergrass by Addition of Micronutrients *. Biomass, 11(7557), 135-146.

Yamada, C., Kato, S., Ueno, Y., Ishii, M., \& Igarashi, Y. (2014a). Conductive iron oxides accelerate thermophilic methanogenesis from acetate and propionate. Jornal of Bioscience and Bioengineering, $x x(\mathrm{xx}), 1-5$. 
Research, Society and Development, v. 10, n. 8, e59910817689, 2021

(CC BY 4.0) | ISSN 2525-3409 | DOI: http://dx.doi.org/10.33448/rsd-v10i8.17689

Yamada, C., Kato, S., Ueno, Y., Ishii, M., \& Igarashi, Y. (2014b). Inhibitory Effects of Ferrihydrite on a Thermophilic Methanogenic Community. Microbes and Environments, 29(2), 227-230. https://doi.org/10.1264/jsme2.ME14026

Yanze-kontchou, C., \& Gschwind, N. (1994). Mineralization of the Herbicide Atrazine as by a Pseudomonas Strain. Applied and Environmental Microbiology, 60(12), 4297-4302.

Yen, H., \& Brune, D. E. (2007). Anaerobic co-digestion of algal sludge and waste paper to produce methane. Bioresource Technology, 98, 130-134. https://doi.org/10.1016/j.biortech.2005.11.010

Zhang, C., Li, M., Xu, X., \& Liu, N. (2015). Effects of carbon nanotubes on atrazine biodegradation by Arthrobacter sp. Journal of Hazardous Materials, 287(April 2015), 1-6. https://doi.org/10.1016/j.jhazmat.2015.01.039 